\title{
Prospective isolation of mouse and human hematopoietic stem cells using Plexin domain containing 2
}

Yosuke Tanaka ${ }^{*}$, Yasushi Kubota ${ }^{2,3 *}$, Ivo Lieberam ${ }^{4}$, Jillian L. Barlow ${ }^{5}$, Josh W.

Bramley $^{5}$, Chiaki Sakuma ${ }^{6}$, Takashi Shibata ${ }^{6}$, Masataka Nakagawa ${ }^{6}$, Yasunori Kurosawa ${ }^{6,7}$, Toshiaki Maruyama ${ }^{7}$, C.J.Okumura ${ }^{7}$, Teruo Akuta ${ }^{6}$, David G. Kent ${ }^{5}$, Thomas M Jessell $^{8}$, Susumu Goyama ${ }^{9}$, Shinya Kimura ${ }^{2}$, Toshio Kitamura ${ }^{1}$

${ }^{1}$ Division of Cellular Therapy, The Institute of Medical Science, Division of Cellular Therapy, The University of Tokyo, Tokyo 108-8639, Japan

${ }^{2}$ Division of Hematology, Respiratory Medicine and Oncology, Department of Internal

Medicine, Faculty of Medicine, Saga University, Saga 849-8501, Japan

${ }^{3}$ Department of Transfusion Medicine and Cell Therapy, Saitama Medical Center,

Saitama Medical University, Kawagoe 350-8550, Japan

${ }^{4}$ Sobell Department of Motor Neuroscience and Movement Disorders, University

College London (UCL) Institute of Neurology, London, UK

${ }^{5}$ Department of Biology, York Biomedical Research Institute, University of York, Wentworth Way, York, UK, YO10 5DD

${ }^{6}$ Kyokuto Pharmaceutical Industrial Co., Ltd., 7-8 Nihonbashi Kobunacho, Chuo-ku, Tokyo 103-0024, Japan

${ }^{7}$ Abwiz Bio, Inc., 9823 Pacific Heights BLVD, Suite J, San Diego, CA 92121, USA

${ }^{8}$ Howard Hughes Medical Institute, Zuckerman Institute, Departments of Neuroscience, and Biochemistry and Molecular Biophysics, Columbia University, New York, NY 10032, USA.

${ }^{9}$ Division of Molecular Oncology Department of Computational Biology and Medical Sciences, Graduate School of Frontier Sciences, The University of Tokyo, Tokyo 1088639, Japan

*Correspondence 


\title{
Summary
}

To date, few molecules are available for isolation of HSCs across species. The present study shows that $P L X D C 2$ is a highly useful molecule for isolation of HSCs, which works across mouse and human.

\begin{abstract}
Numerous strategies exist to isolate hematopoietic stem cells (HSCs) using complex combinations of markers and flow cytometry. However, robust identification of HSCs using imaging techniques is substantially more challenging which has prompted the recent development of HSC reporter mice. To date, none of the molecules used in these reporters have been useful for human HSC identification. Here we report that PLXDC2 is a useful marker for both mouse and human HSCs. Using a green fluorescent protein (GFP) knock-in at the Plxdc2 locus in mice (hereafter denoted as Plxdc2-GFP), we showed that Plxdc2-GFP is highly expressed in HSCs with 1 in $2.8 P l x d c 2-\mathrm{GFP}^{+} \mathrm{CD} 150^{+}$ cells giving long-term multi-lineage reconstitution in transplantation. Moreover, we developed a novel human PLXDC2 antibody and showed that human PLXDC2 ${ }^{+}$HSCs have stronger long-term multilineage reconstitution ability compared with PLXDC2HSCs in a xenograft model. Thus, our study identifies PLXDC2 as a highly relevant molecule in HSC identification, potentially allowing greater purity and live in vivo tracking of these cells.
\end{abstract}




\section{Introduction}

A key aspect of stem cell biology is the definition of the different phenotypic and functional compartments, especially the most immature compartment, which replenishes all cells within a given tissue. In this regard, hematopoietic stem cells (HSCs) are the most comprehensively characterized tissue stem cell. Over the past three decades, the identification of HSCs has been improved by using both multicolor fluorescenceactivated cell sorting analysis (FACS) and the in vivo bone marrow (BM) repopulation assay (Spangrude et al., 1988; Osawa et al., 1996; Spangrude, 1995; Kiel et al., 2005; Mayani and Dragowska, 1993; Baum and Peault, 1992; Craig et al., 1993; Majeti et al., 2007; Hao et al., 1995; Bhatia et al., 1997; Notta et al., 2011; Visser et al., 1984). c-Kit ${ }^{+}$, Sca- $1^{+}$, lineage marker- $(\mathrm{KSL})$ cells represented the first major step in HSC identification, but have been further enriched by additional negative (CD34 (Osawa et al., 1996), Flk2 (Christensen and Weissman, 2001), CD48 and CD41 (Kiel et al., 2005)) and positive (CD150 (Kiel et al., 2005), CD105 (Chen et al., 2002), CD201(Balazs et al., 2006) and Esam1 (Yokota et al., 2009; Ooi et al., 2009)) markers. Most of the FACS-based HSC purification methods use the $\mathrm{CD} 150^{+} \mathrm{CD} 34^{\text {low/- }} \mathrm{c}-\mathrm{Kit}{ }^{+} \mathrm{Sca}-{ }^{+}$lineage marker-negative (Lin-) BM population to purify adult mouse HSCs, which contain cells with long-term multilineage reconstitution and self-renewal ability (Kiel et al., 2005; Morita et al., 2010; Yamamoto et al., 2013). However, the $\mathrm{CD} 150^{+} \mathrm{CD} 34^{\text {low/- }}{ }^{-}-\mathrm{Kit}^{+} \mathrm{Sca}-1^{+} \mathrm{Lin}^{-} \mathrm{BM}$ cells still contain non-long term HSCs (LT-HSC). Additionally, identification of negatively stained cells is straightforward with FACS analysis but is substantially more complicated with non-quantitative immunofluorescence on fixed and embedded tissue sections despite the 
urgent need to understand HSC behavior in the context of the in vivo HSCmicroenvironment (niche). Several HSC-specific reporters such as Fgd5-mCherry or ZsGreen, Hoxb5-mCherry, and $\alpha$-catulin-GFP already exist as powerful tools for visualizing HSCs throughout the BM (Gazit et al., 2014; Chen et al., 2016; Acar et al., 2015). However, these elegant HSC visualization technologies are not readily accessible to all researchers because they require genetically modified mice. Therefore, simple methods using a few antibodies for positive HSC markers are preferable to meet the above requirements.

Human transplantation and xenograft repopulation assays show that human HSCs are $\mathrm{CD} 34^{+}$, but the majority of $\mathrm{CD} 34^{+}$cells are lineage-restricted progenitors and HSCs consist of a minor component of the population. The standard purification strategy to date for human HSCs uses the cell surface marker profile Lin-CD34 ${ }^{+}$CD $38^{-}$ CD90 $^{+}$CD45RA $^{-}$(Notta et al., 2011; Chao et al., 2008; Baum et al., 1992; Craig et al., 1993; Majeti et al., 2007) and the most recent purification method for human HSCs uses CD49f in addition to these markers to arrive at a population that is $\sim 10 \%$ functional HSCs when human cord blood is used as the starting material (Notta et al., 2011). While this is a major milestone, the enriched $\mathrm{CD} 4^{+} \mathrm{CD} 38^{-} \mathrm{CD} 90^{+} \mathrm{CD} 45 \mathrm{RA}^{-} \mathrm{CD} 49 \mathrm{f}^{+}$population remains heterogeneous than mouse HSCs, therefore requiring new markers to further purify functional human HSCs.

Our previous screening on HSC-specific genes identified several cell surface genes (Kubota et al., 2009). We noted plexin domain containing 2 (Plxdc2) among them. PLXDC2 is a single-pass type I membrane protein which encodes a 350-amino acid long 
plasma membrane protein. PLXDC2 plays an important role in cell proliferation and differentiation during nervous system development (Miller et al., 2007; Miller-Delaney et al., 2011). PLXDC2 is also known as one of the membrane receptors of pigment epithelial-derived factor (PEDF), an endogenous anti-angiogenesis factor (Cheng et al., 2014). Moreover, PLXDC2 is an activating ligand for an adhesion G-protein coupled receptor D1 (Adgrd11) displayed on cumulus cells (Bianchi et al., 2021). In addition, PLXDC2 has a regulatory function and a significant impact on modulation of the host immune response against Helicobacter pylori (Tubau-Juni et al., 2020). However, the function of PLXDC2 in the hematopoietic system remains unknown.

In the present study, we identified PLXDC2 as a HSC purification marker using a Plxdc2-GFP knock-in mouse line (Miller-Delaney et al., 2011) and found that the combination of two positive markers, Plxdc2-GFP and CD150, provided sufficient purification of functional HSCs without any additional markers. Moreover, PLXDC2 was also highly expressed in human HSCs derived from both cord blood and BM. We showed that the anti-PLXDC2 antibody, clone 4G3 which we previously developed, was useful for further purification of human functional HSCs from the conventional human HSC fraction.

\section{Results}

\section{Plxdc2 is highly expressed in mouse HSCs}

Our previous gene expression analysis between CD34- KSL cells as HSCs and other hematopoietic cells identified HSC-specific genes (Kubota et al., 2009). In the present 
study, we studied Plexin domain containing $2(P l x d c 2)$ as a candidate surface marker for purification of HSCs among them. PLXDC2 is a single pass type I membrane protein which is expressed in tumor vessels but not in most normal tissues. Quantitative reverse transcription PCR revealed that Plxdc2 was highly expressed in CD34-KSL cells and $\mathrm{CD}^{+} \mathrm{CD}^{+}$double positive T cells in mouse hematopoietic cells (Figure 1A). We further confirmed that Plxdc2 was highly expressed in long-term HSCs (LT-HSCs) compared with short term HSCs (ST-HSCs), multipotent progenitors (MPPs) and progenitors (Figure 1B). Moreover, public gene expression data showed that Plxdc2 was highly expressed in HSCs and mesenchymal cells in mouse BM (Figures S1A, S1B and S1C).

To assess $P l x d c 2$ expression in hematopoiesis in detail, we analyzed Plxdc2GFP knock-in mice (Miller-Delaney et al., 2011). Both Plxdc2 $2^{G F P /+}$ and $P l x d c 2^{G F P / G F P}$ mice were born and survived into adulthood with expected Mendelian frequencies. $P l x d c 2^{G F P /+}$ and $P l x d c 2^{G F P / G F P}$ mice showed normal hematopoiesis (Tables S1 and S2). Colony-forming assay of whole BM cells revealed no significant difference between $P l x d c 2^{+/+}$and Plxdc2 $2^{G F P / G F P}$ littermates in the frequency of lineage-restricted

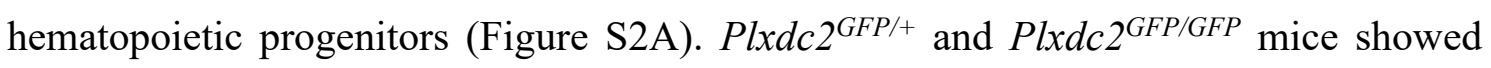
normal HSC frequency and normal HSC function upon transplantation into lethally irradiated mice (Figures S2B and S2C).

Mature hematopoietic cells in the BM from $P l x d c 2^{G F P /+}$ mice did not express Plxdc2-driven GFP (hereafter referred to as "Plxdc2-GFP"), whereas most of the T cells except $\mathrm{CD}^{-\mathrm{CD}}{ }^{-}{ }^{-}-\mathrm{Kit}^{-} \mathrm{CD} 25^{-}$cells in the thymus expressed Plxdc2-GFP (Figures S3A and S3B). Overall, just $0.19 \%$ of total BM cells in Plxdc2 $2^{G F P /+}$ mice were Plxdc2-GFP ${ }^{+}$ 
(Figure 1C). Neither common lymphoid progenitors (CLPs) nor myeloid progenitors (MPs) expressed Plxdc2-GFP (Figure S3C). Plxdc2-GFP expression was highly enriched in KSL cells $(9.23 \%)$, CD150 ${ }^{+} \mathrm{KSL}$ cells $(43 \%)$ and CD34-CD150 ${ }^{+} \mathrm{KSL}$ cells $(72.7 \%)$ suggesting that it was highly enriched in LT-HSCs (Figure 1D). Of note, Plxdc2-GFP expression in KSL cells was negatively correlated with CD34 expression and most of the Plxdc2-GFP cells were CD150+ (Figure 1E), further supporting the notion that Plxdc2$\mathrm{GFP}^{+}$cells are highly enriched in HSCs.

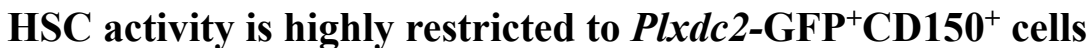

To examine HSC potential of Plxdc2-GFP ${ }^{+}$cells in the BM, 500 Plxdc2-GFP ${ }^{+}$cells or $2 \times 10^{5}$ Plxdc2-GFP- cells were transplanted into lethally irradiated mice alongside $2 \times 10^{5}$ competitor cells (Figure 2A). Long-term multilineage chimerism was observed in peripheral blood (PB) from Plxdc2-GFP ${ }^{+}$cell-transplanted mice over 21 weeks, whereas only short-term lymphoid lineage chimerism was observed at low levels in PB from Plxdc2-GFP- cell-transplanted mice (Figure 2B). Limiting dilution analysis revealed that 1 in 3.53 Plxdc2-GFP ${ }^{+}$KSL cells gave long-term multilineage reconstitution of irradiated primary recipients (Figure 2D) and single-cell transplantations showed that 1 in 2.05 Plxdc2-GFP ${ }^{+} \mathrm{CD} 150^{+} \mathrm{KSL}$ cells gave long-term multilineage reconstitution of irradiated primary recipients. To simply the purification method of HSCs to a two-color strategy, we assessed the combination of Plxdc2-GFP and CD150. Nearly all of the Plxdc2$\mathrm{GFP}^{+} \mathrm{CD} 150^{+}$cells were also $\mathrm{CD} 34^{-} \mathrm{CD} 150^{+} \mathrm{KSL}$ cells and Plxdc2-GFP ${ }^{+} \mathrm{CD} 150^{-}$cells were c-Kit ${ }^{-}$cells (Figure 2C). Limiting dilution analysis of the Plxdc2-GFP ${ }^{+} \mathrm{CD} 150^{+}$ 
fraction of whole BM cells revealed that the HSC frequency of Plxdc2-GFP $\mathrm{CD}^{+} 50^{+}$cells was 1 in 2.8 (Figure 2D). Single cell transplantation studies revealed that $44.7 \%(17 / 38)$ of Plxdc2-GFP ${ }^{+} \mathrm{CD} 150^{+}$cells and $48.8 \%(21 / 43)$ of $P l x d c 2-\mathrm{GFP}^{+} \mathrm{CD} 150^{+} \mathrm{KSL}$ were functional HSCs capable of long-term multi-lineage reconstitution (Figure 2D), indicating that $\mathrm{Plxdc2}-\mathrm{GFP}^{+} \mathrm{CD} 150^{+}$fraction was roughly equivalent to Plxdc2$\mathrm{GFP}^{+} \mathrm{CD} 150^{+} \mathrm{KSL}$ fraction. Collectively, these data suggest that Plxdc2-GFP ${ }^{+} \mathrm{CD} 150^{+}$ cells in the whole BM are functional HSCs and therefore the combination of Plxdc2-GFP and CD150 is sufficient to purify functional HSCs in the whole BM.

\section{Plxdc2 stably marks mobilized HSCs.}

To further extend analysis for clinical setting, we examined whether Plxdc2-GFP also marked mobilized HSCs in the spleen after cyclophosphamide/granulocyte-colony stimulating factor (G-CSF) treatment. To this end, we administered a single dose of cyclophosphamide on day 0 and constitutive administration of G-CSF for one week from day 1 and then analyzed Plxdc2-GFP expression in mobilized HSCs in the spleen (Figure 3A). No Plxdc2-GFP ${ }^{+}$cells were detected in spleen in the steady state condition, whereas $0.11 \%$ of cells were Plxdc2-GFP ${ }^{+}$after administration of G-CSF (Figure 3B). 8.15\% of mobilized KSL cells in the spleen expressed Plxdc2-GFP and CD150. 500 Plxdc2-GFP ${ }^{+}$ cells isolated from mobilized spleen gave long-term multi-lineage chimerism in lethally irradiated mice, whereas $2 \times 10^{5}$ cells of Plxdc2-GFP- cells in mobilized spleen contained no HSCs (Figures 3C and 3D). These data indicate that Plxdc2-GFP expression constantly marks HSCs in the mobilization condition. 


\section{$P L X D C 2$ expression is enriched in functional human HSCs}

In order to determine whether PLXDC2 is relevant for human HSCs, we extended our analysis by first assessing its expression using newly established rabbit monoclonal antibody for human PLXDC2 (Shimizu et al., 2018). PLXDC2 expression was highest on the conventional human $\mathrm{HSCs}\left(\mathrm{CD} 34^{+} \mathrm{CD} 38^{-} \mathrm{CD} 90^{+} \mathrm{CD} 45 \mathrm{RA}^{-} \mathrm{CD} 90^{+} \mathrm{CD} 49 \mathrm{f}^{+}\right.$cells) among hematopoietic stem and progenitor cells (HSPCs) (Figures 4A and S4A). Unlike in mouse, $P L D X C 2$ expression was not entirely restricted to the HSC compartment with some expression in progenitor cells and $\mathrm{CD} 14^{+}$monocytes (Figures S4B, S4C and S4D). Flow cytometric analysis of the human peripheral blood mononuclear cells (PBMCs) showed that PLXDC2 was detected on CD41 ${ }^{+}$cells $(12.6 \%)$, CD56 ${ }^{+}$cells $(2.8 \%), \mathrm{CD} 19^{+}$ cells $(13.9 \%), \mathrm{CD}^{+}$cells $(3.05 \%), \mathrm{CD} 33^{+} \mathrm{CD} 66 \mathrm{~b}^{-}$cells $(15.5 \%)$ and $\mathrm{CD} 14^{+} \mathrm{CD} 15^{+}$cells (49.4\%) (Figure S4E). In order to test whether PLXDC2 expression tracked with HSC function, we separated human HSCs derived from cord blood into PLXDC2 ${ }^{+/ \text {high }}$ (referred to here as $\mathrm{PLXDC}^{+}$) and PLXDC2 $2^{- \text {low }}$ (referred to here as PLXDC2-) and performed functional assays (Figure 4B). We first evaluated their hematopoietic colony-forming capacity in serial replating assays. PLXDC2- cells formed 1.6-fold more colonies than $\mathrm{PLXDC}^{+}$cells in the first round. In contrast, PLXDC2 ${ }^{+}$cells formed 1.6-fold more colonies than PLXDC2- cells in the second round of plating (Figure 4C), suggesting that $\mathrm{PLXDC}^{+}$cells were more immature than PLXDC2 ${ }^{-}$cells. We next evaluated their capacity for long-term multilineage reconstitution by transplanting them into NOD-scid-

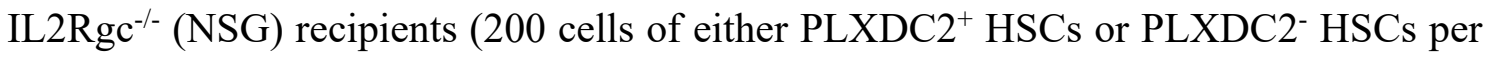


mice). PLXDC2 ${ }^{+}$cells gave higher human $\mathrm{CD} 45^{+}$chimerism in peripheral blood than PLXDC2 ${ }^{-}$cells during the observation period (Figure 4D). Although levels of chimerism remained high in the peripheral blood of mice transplanted with PLXDC2 ${ }^{+}$HSCs, engraftment of PLXDC2- HSCs peaked at 2 months and then declined. The chimerism pattern of PLXDC2- HSCs indicated that PLXDC2- HSCs were mainly short-term HSCs. Moreover, PLXDC2 $2^{+}$cells gave much higher mean chimerism in hematopoietic organs than PLXDC2 ${ }^{-}$cells (Figure 4E). PLXDC2 ${ }^{+}$cells gave more B cell output (Chimerism of $\mathrm{CD}^{+} 9^{+}$cells) than PLXDC2- cells (Figure 4F) whereas erythrocyte output was similar between $\mathrm{PLXDC}^{+}$and $\mathrm{PLXDC}^{-}$cells (Figure 4G). Limiting dilution assays demonstrated that 1 in $49.9 \mathrm{PLXDC}^{+}$cells could give rise to long-term multilineage engraftment compared with 1 in 249.1 $\mathrm{PLXDC}^{-}{ }^{-}$cells $(\mathrm{P}=0.00348$, Figure $4 \mathrm{H})$. Our HSC frequency $(2 \%)$ was much less than that shown in Dick group (10\%) (Notta et al., 2011). This discrepancy may be due to differences in experimental conditions such as an irradiation dose and an injection method. Taken together, PLXDC2 expression could further separate functional human $\mathrm{HSCs}$ within the conventional $\mathrm{CD} 34^{+} \mathrm{CD} 38^{-}$ $\mathrm{CD}^{+} 0^{+} \mathrm{CD} 45 \mathrm{RA}^{-} \mathrm{CD} 49 \mathrm{f}^{+}$fraction.

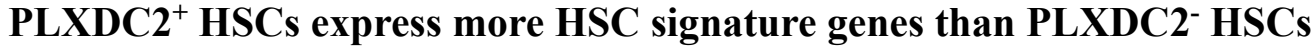

To examine transcriptomic differences between PLXDC2 ${ }^{+}$and PLXDC2- HSCs, we performed RNA-Seq analysis. Although transcriptomes of $\mathrm{PLXDC}^{+} \mathrm{HSCs}$ and PLXDC2- HSCs were highly similar, THBS1, SORBS2, SGSH and SAMHD1 were identified as highly differentially expressed genes (DEGs) in $\mathrm{PLXDC}^{+} \mathrm{HSCs}(\mathrm{FDR}<$ 
0.01), whereas CPA3, ABCA1, CDK6 and IRF8 were highly DEGs in PLXDC2- HSCs

$($ FDR $<0.01)$ (Figures 5A and 5B). Interestingly, CDK6 expression has been shown to mark active HSCs in mouse and human studies (Laurenti et al., 2015; CabezasWallscheid et al., 2017; Fukushima et al., 2019) and IRF8 is a differential marker for myeloid cells (Kurotaki et al., 2013; Kurotaki et al., 2018). The gene expression data therefore suggest that PLXDC2- HSCs express a more differentiated gene signature than PLXDC2 ${ }^{+}$HSCs. Interestingly, although functions of THBS1, SORBS2, SGSH and SAMHD1 in HSCs were not well understood, but their functions were related with important HSC signatures such as active TGF $\beta$ signaling, adhesion character, activation of lysosomal function and resistance to viral infection (Table S3). Next, we investigated the biological pathways differentially represented between $\mathrm{PLXDC2}^{+} \mathrm{HSCs}$ and PLXDC2- HSCs using gene set enrichment analysis (GSEA) (Figure 5C, FDR < 0.1). Again, PLXDC2 ${ }^{+}$HSCs showed an enrichment for the HSC signature. Conversely, we found downregulation of essential biosynthetic processes such as mRNA processing, oxidative phosphorylation and MYC targets in $\mathrm{PLXDC}^{+} \mathrm{HSCs}$ compared with PLXDC2- HSCs. Together, these data reinforce the functional data above, indicating that the $\mathrm{PLXDC}^{+}$fraction contain more cells expressing HSC-related genes than the PLXDC2- fraction.

\section{Discussion}

Our study shows that PLXDC2 is a useful marker for identifying both mouse and human HSCs. Because of the limited availability of human HSCs in the BM or fetal liver and 
their different purification methods from those of mouse HSCs, features of human HSCs are not well understood. In order to make robust comparisons across species, it is therefore essential to identify common markers. To date, however, only a few common markers, such as EPCR and ESAM, have been reported (Yokota et al., 2009; Balazs et al., 2006; Georgantas et al., 2004; Fares et al., 2014; Fares et al., 2017; Ishibashi et al., 2016). Interestingly, these markers, including PLXDC2, are all endothelial markers, suggesting that HSCs retain some aspects of an endothelial program, which is perhaps reflective of their origin from endothelial cells during development and may be a useful feature that allows their discrimination from other hematopoietic cells. Therefore, developing common purification methods between mouse and human HSCs using these endothelial markers is useful for furthering our understanding of human HSCs.

PLXDC2 in combination with CD150 is enough to highly purify mouse functional HSCs compared with the conventional multi-antibody combination. 1 in 2.8 Plxdc2-GFP ${ }^{+} \mathrm{CD} 150^{+}$cells in whole BM were functional HSCs (Figure 2D). This HSC frequency is equivalent to the frequency reported using $\alpha$-catulin in combination with cKit (1 in 3.1 cells) (Acar et al., 2015) and collectively represent the best two-color strategies to date. That said, PLXDC2 is a more attractive marker for purification of HSCs than $\alpha$-catulin because PLXDC2 is a membrane protein, whereas $\alpha$-catulin is an intracellular protein. In this study, we developed a flow cytometry approach using a recently available anti-human PLXDC2 antibody. Unfortunately, this antibody does not uniformly recognize mouse $P l x d c 2$ despite homology between mouse and human PLXDC2 being over $90 \%$, suggesting that another antibody in the future may be able to 
universally detect both mouse and human PLXDC2. One possible reason for this discrepancy is that PLXDC2 has been reported to be a substrate of $\gamma$-secretase and $\beta$-site amyloid precursor protein (APP) cleaving enzyme 1 (BACE-1), which cleaves the extracellular domains of membrane proteins (Hemming et al., 2008; Dislich et al., 2015). This suggests that mouse Plxdc2 on HSCs may be cleaved by these enzymes and that using inhibitors of these enzymes before purification might be useful in future studies. Nonetheless, developing a flow cytometric analysis-available antibody against mouse PLXDC2 will allow us to highly purify mouse functional HSCs in combination with CD150 and to easily detect mouse functional HSCs without the need for a reporter mouse. Our two-color strategy is also useful for imaging studies. It is hoped that the new antibody will improve the sensitivity and enable HSC detection.

Our study also shows that PLXDC2 further purifies human HSCs from the conventional human $\mathrm{CD}^{+} 4^{+} \mathrm{CD} 38^{-} \mathrm{CD} 90^{+} \mathrm{CD} 45 \mathrm{RA}^{-} \mathrm{CD} 49 \mathrm{f}^{+}$fraction, which are most purified faction for human functional HSCs to date. The finding that further enrichment of functional human HSCs could be achieved by using an anti-PLXDC2 antibody will aid researchers looking to further purify functional human HSCs for cellular and molecular studies. Moreover, PLXDC2 ${ }^{+}$HSCs showed a negative correlation with gene signatures for mRNA processing, upregulation of Myc-regulated genes and oxidative phosphorylation, indicating that $\mathrm{PLXDC} 2^{+} \mathrm{HSCs}$ are likely to be quiescent (Figure 5C). In addition, the mature cell output ratio between $\mathrm{B}$ cells and myeloid cells in PLXDC2 ${ }^{+}$ HSCs was B lymphoid dominant, consistent with that of conventional CD34 $4^{+} \mathrm{CD} 38^{-}$ $\mathrm{CD}^{+} \mathrm{CD}^{+} 45 \mathrm{RA}^{-} \mathrm{CD} 49 \mathrm{f}^{+}$HSCs. In contrast, repopulation in PLXDC2- HSCs was 
balanced, which could be explained by higher expression of IRF8 in PLXDC2- HSCs compared to PLXDC2 $2^{+}$HSCs.

It has been reported that the timing of exit from quiescence in human HSC subsets is controlled by CDK6 expression levels (Laurenti et al., 2015). Since PLXDC2HSCs show higher CDK6 expression than PLXDC2 ${ }^{+}$HSCs, this would further suggest that PLXDC2 ${ }^{+}$HSCs are more quiescent than PLXDC2 ${ }^{-}$HSCs. THBS1, SORBS2, SGSH and SAMHD1 were highly differentially expressed in PLXDC2 ${ }^{+} \mathrm{HSCs}$ as compared with PLXDC2- HSCs. THBS 1 is known to activate latent TGF $\beta$ (Murphy-Ullrich and Poczatek, 2000) and active TGF $\beta$ is essential for maintenance of HSCs (Yamazaki et al., 2011). SORBS2 (Sorbin and SH3 Domain Containing 2), also known as ArgBP2, is an adapter protein that can localize to both focal adhesions and actomyosin filaments (Wang et al., 1997) and suppresses ovarian cancer metastasis (Zhao et al., 2018). Defect of focal adhesion alters maintenance of HSCs (Lu et al., 2012; Batista et al., 2014). These features might be involved in adhesion in niche cells and hibernation of HSCs. SGSH encodes Nsulfoglucosamine sulfohydrolase; one of several enzymes involved in the lysosomal degradation of heparan sulfate. SGSH mutations causes the Sanfilippo syndrome, or mucopolysaccharidosis III, which is a lysosomal storage disease due to impaired degradation of heparan sulfate. HSC daughter cells with low levels of lysosomes after asymmetric cell division are induced to differentiate, indicating that lysosomes are important for maintenance of stemness (Loeffler et al., 2019). Therefore, high expression of SGSH in PLXDC2 $2^{+}$HSCs indicates that lysosome in PLXDC2 $2^{+} \mathrm{HSCs}$ is more active than that in PLXDC2- HSCs. The sterile alpha motif (SAM) domain and HD domain- 
containing protein 1 (SAMHD1) is a potent restriction factor for human immunodeficiency virus (Laguette et al., 2011; Hrecka et al., 2011). SAMHD1 is also known as an interferon stimulated gene and exclusively expressed in HSCs (Wu et al., 2018). Collectively, high expression of these 4 genes is likely to contribute to maintain the stem cell phenotype in PLXDC2 $2^{+}$HSCs.

Taken together, our data show that $P l x d c 2$ is a potent marker for enrichment of both mouse and human HSCs. Until we have common markers across species, we will be limited in our ability to make comparisons between mouse and human HSCs. Therefore, finding of PLXDC2 as a common marker between mouse and human has a great impact in this regard.

\section{Acknowledgements}

We thank Shiori Shikata and Akiho Tsuchiya for expert technical assistance. We thank the IMSUT FACS Core Laboratory and the IMSUT Animal Research Center. This work was supported by a Grant-in-Aid for Challenging Exploratory Research (17K19645, Y.T.), KAKENHI grant number (20K07639, Y.K.), a grant from The SENSHIN Medial Research Foundation (Y.T.), a grant from Leukemia Research Fund (S.G.), Tokyo Metropolitan Small and Medium Enterprise Support Center (T.A. and Y.T.) and MRCAMED joint award (MR/V005502/1) (DG.K. and Y.T). We finally thank Shin-ichi Nishikawa for supervision of starting this study.

\section{Author contributions}


Conceptualization and Methodology, Y.T., T.A. and Y.K.; Investigation, Y.T., Y.K., JL.B., and JW.B.; Visualization, C.S., T.S., M.N., Y.K., T.M., T.A.; Writing - Original Draft, Y.T.; Writing - Review \& Editing, Y.T., Y.K., and DG.K.; Funding Acquisition, Y.T., T.A., DG.K. and Y.K.; Resources, Y.T., Y.K., S.G., I.L., C.S., T.S., M.N., Y.K., T.M., C.J.O., T.A. and T.M.J.; Supervision, S.N. S.K. T.A. and T.K.

\section{Declaration of Interests}

The authors declare no competing interests. 


\section{Figure legends}

Figure1

A

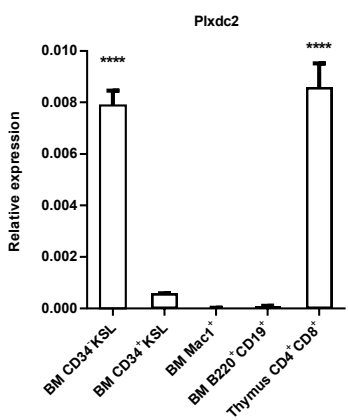

B

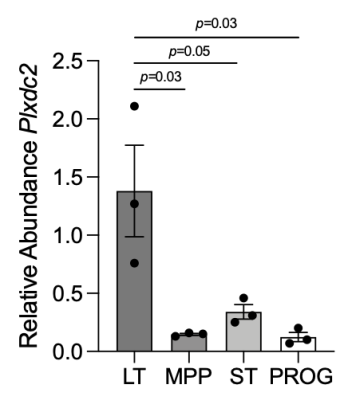

$\mathrm{E}$
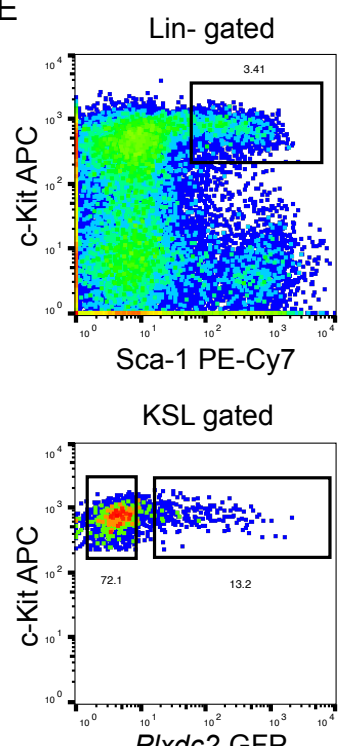

C

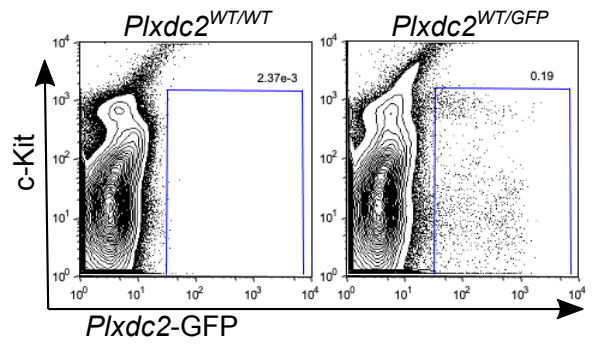

D
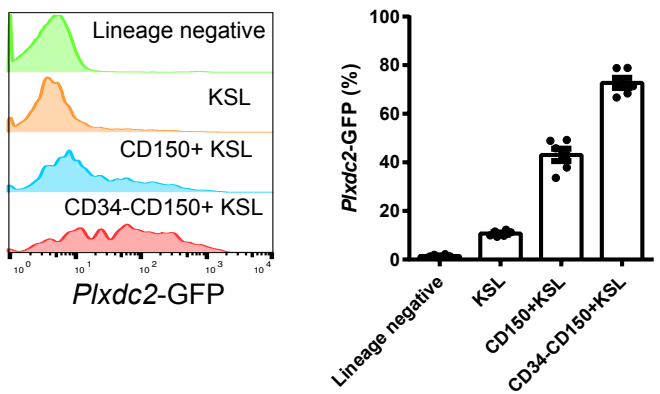

KSL gated

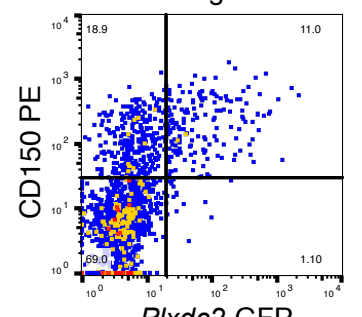

Plxdc2-GFP

KSL gated

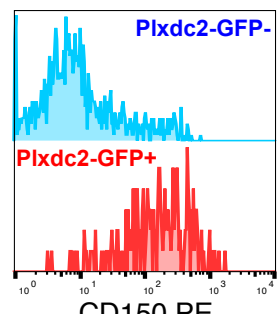

$\mathrm{CD}^{10^{10^{2}}} \mathrm{PE}$

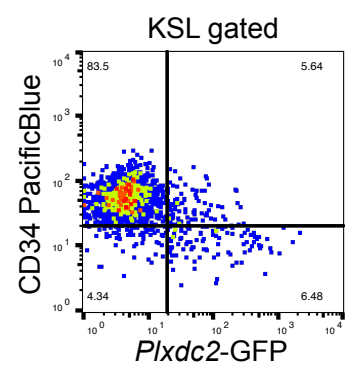

KSL gated

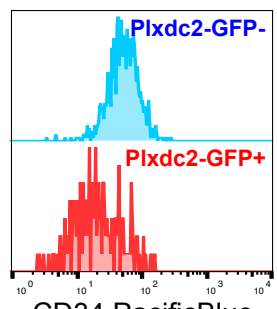

CD34 PacificBlue 


\section{Figure 1. Plxdc2 is enriched for functional HSCs}

(A and B) Quantitative PCR analysis showing the abundance of Plxdc2 relative to Hprt in the indicated populations in BM and thymus (A) and in populations of BM stem and progenitor cells (B). LT: LT-HSCs ( Lin $\left.^{-}-\mathrm{Kit}^{+} \mathrm{Sca} 1^{+} \mathrm{CD} 135^{-\mathrm{CD}} 34^{-}\right)$, MPP: Multipotent progenitor cells $\left(\mathrm{Lin}^{-} \mathrm{c}-\mathrm{Kit}^{+} \mathrm{Sca}{ }^{+} \mathrm{CD} 135^{+} \mathrm{CD} 34^{+}\right)$, ST: ST-HSCs $\left(\mathrm{Lin}^{-} \mathrm{c}-\mathrm{Kit}^{+} \mathrm{Sca}{ }^{+} \mathrm{CD} 135^{-}\right.$ $\mathrm{CD}^{+}$), and PROG: Progenitors (CMP, GMP, and MEP, Lin`c-Kit ${ }^{+} \mathrm{Scal}^{-}$). (C) Representative FACS plots of Plxdc2-GFP ${ }^{+}$cells in the BM. Left: $P l x d c 2^{+/+}$mice, right: $P l x d c 2^{+/ G F P}$ mice. (D) The percentage of Plxdc2-GFP ${ }^{+}$cells in the indicated cell types. Left: representative FACS plots, right: a bar plot ( $n=6$ each). (E) Representative FACS plots for expression of HSC markers on Plxdc2-GFP ${ }^{+}$cells. Expression profiles of KSL cells for Plxdc2-GFP, CD34 and CD150 (upper panels). Expression profiles of Plxdc2 ${ }^{+}$ KSL cells (blue) and Plxdc2- KSL cells (red) for CD34 and CD150 (lower panels). Data are shown as the mean \pm SEM. P values were calculated using one-way ANOVA with Tukey's correction for multiple comparisons. $* \mathrm{P}<0.05, * * \mathrm{P}<0.01$, *** $\mathrm{P}<0.001$, **** $\mathrm{P}<0.0001$ 


\section{Figure2}
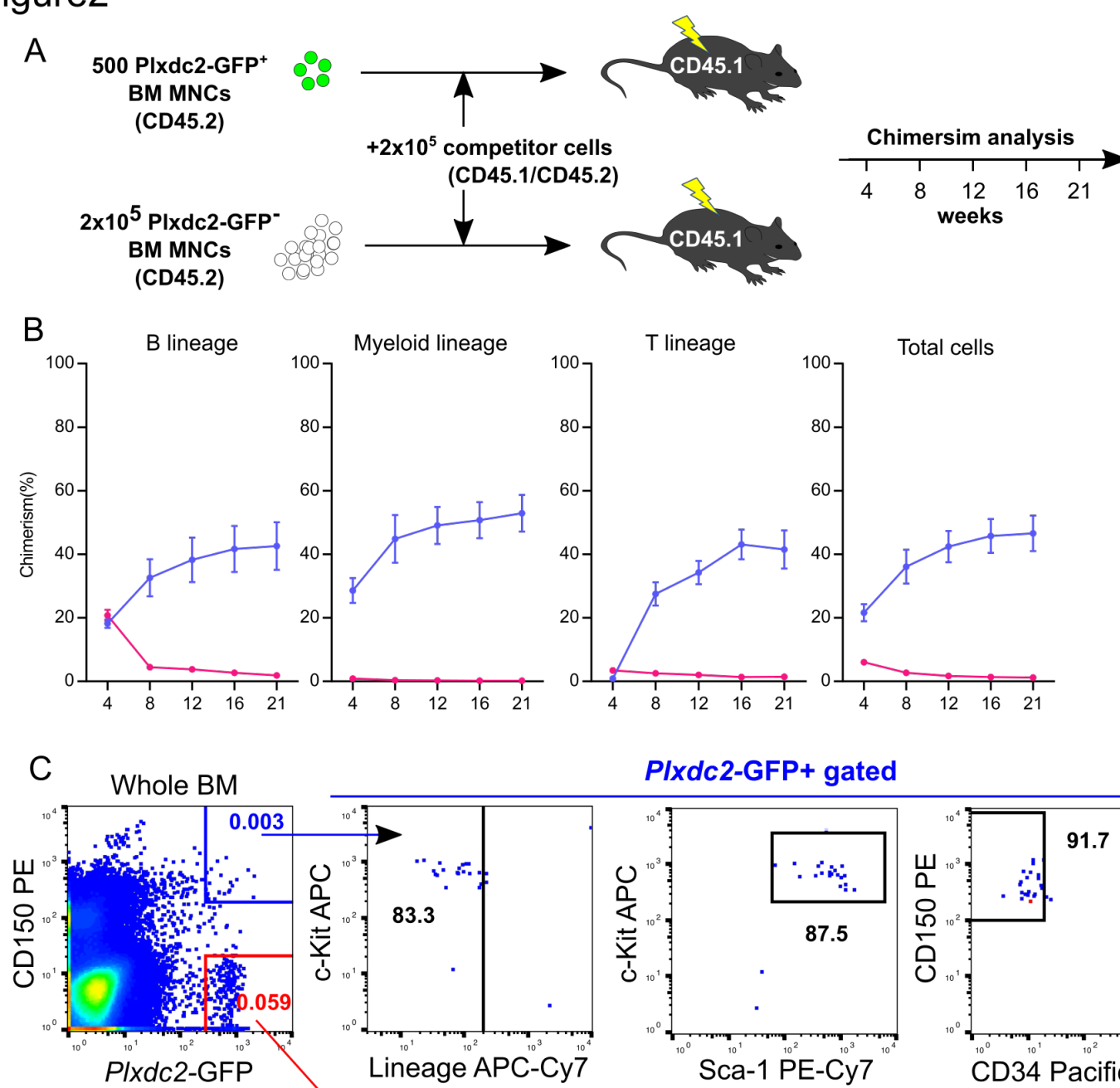

Plxdc2-GFP+ gated
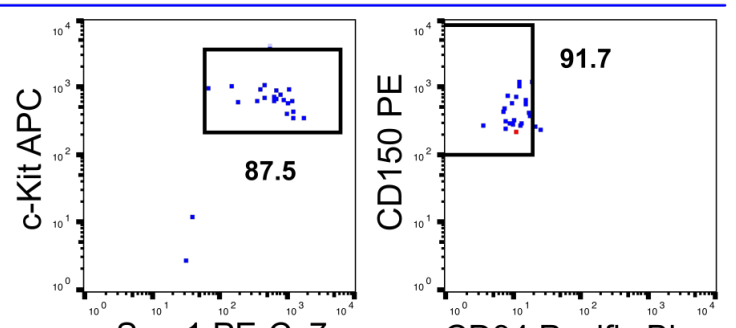

Sca-1 PE-Cy7

CD34 Pacific Blue

PIxdc2-GFP+ gated
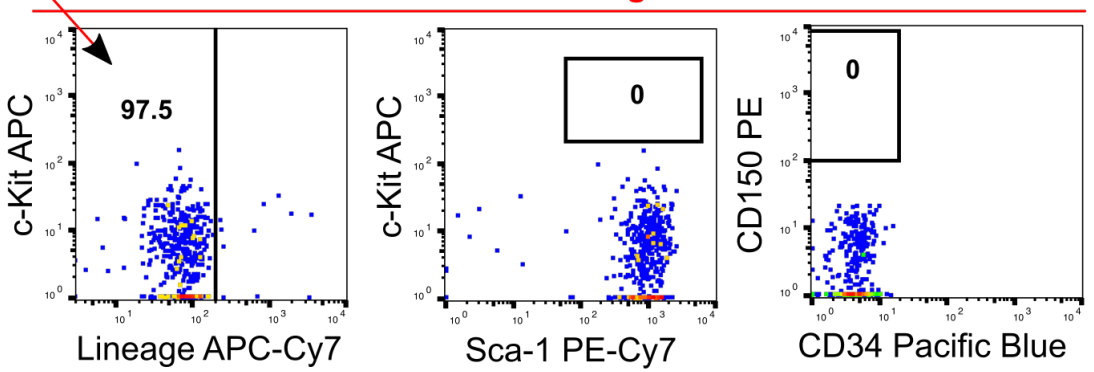

D

Sca-1 PE-Cy7

CD34 Pacific Blue

\begin{tabular}{cccc}
\hline Donor cell population & Donor cell dose LTMR/transplanted mice HSC frequency \\
\hline PIxdc2-GFP ${ }^{+}$c-Kit ${ }^{+}$Sca-1 ${ }^{+}$Lin $^{-}$ & 10 & $8 / 9$ & 1 in 3.5 \\
& 5 & $9 / 12$ & \\
\hline PIxdc2-GFP ${ }^{+}$CD150 & 3 & $18 / 27$ & 1 in 2.8 \\
& 5 & $9 / 12$ & \\
\hline PIxdc2-GFP CD150 & & $11 / 15$ & 1 in 2.05 \\
Sca-1 $^{+}$Lin $^{-}$ & 3 & $17 / 38$ \\
\hline
\end{tabular}




\section{Figure 2. Plxdc2-GFP ${ }^{+}$cells are highly enriched for functional HSCs}

(A) Experimental design. (B) Chimerism kinetics of donor cells in the indicated lineages.

(C) Expression profiles of Lin, c-Kit, Sca-1, CD34 and CD150 on Plxdc2-GFP ${ }^{+}$whole

BM cells and Plxdc2-GFP- whole BM cells. (D) The indicated number of the indicated cells from Plxdc2 $2^{+/ G F P}$ mice (CD45.2) were transplanted into lethally irradiated recipients (CD45.1) along with $2 \times 10^{5}$ whole BM cells (CD45.1/CD45.2). Recipients were considered long-term multilineage reconstituted when donor-type myeloid, B, Tlymphoid lineages were present more than $1.0 \%$ for 16 weeks after transplantation. The frequency of cells that reconstituted was calculated based on limit-dilution (Poisson) statistics (Smith et al., 1991). 
bioRxiv preprint doi: https://doi.org/10.1101/2021.09.27.461900; this version posted September 27, 2021. The copyright holder for this preprint (which was not certified by peer review) is the author/funder, who has granted bioRxiv a license to display the preprint in perpetuity. It is made available under aCC-BY-NC-ND 4.0 International license.

Figure 3

A

Day0

Day1

Day7

Cyclophosphamide (200mg/kg ip)
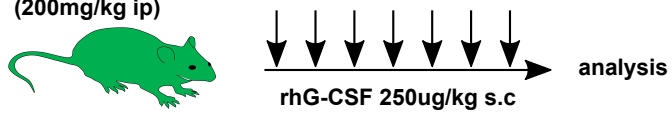

B
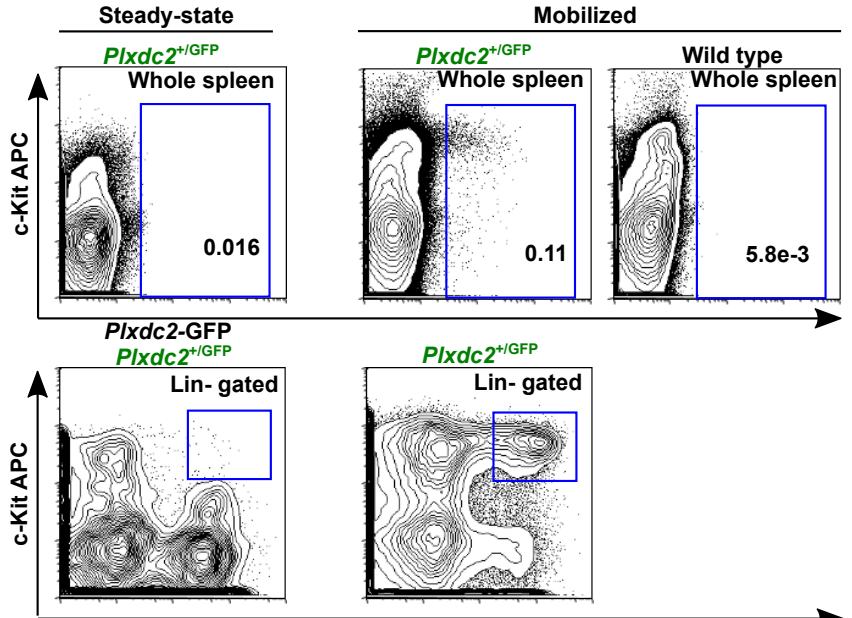

Sca-1

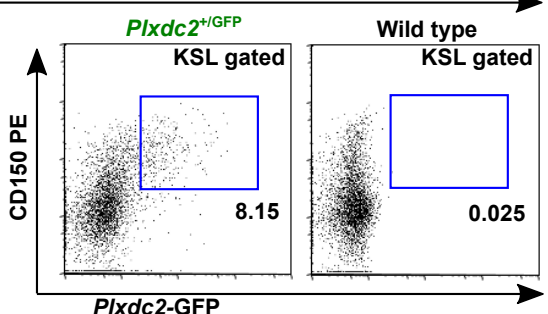

C

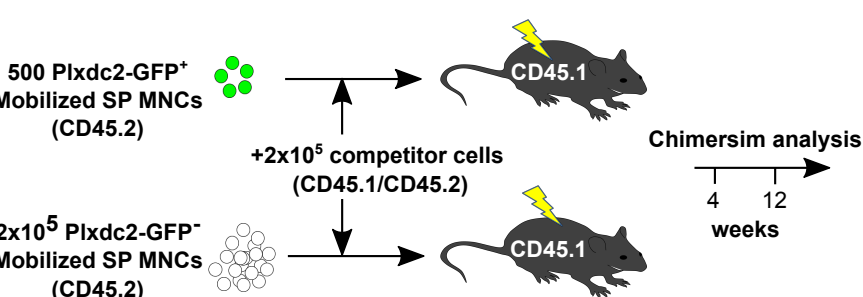

D

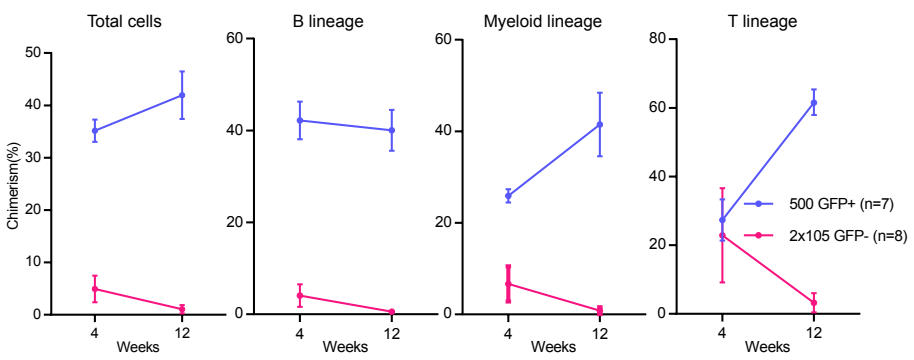




\section{Figure3: Plxdc2-GFP marks mobilized HSCs}

(A) Experimental design of G-CSF administration. (B) Representative FACS plots for Plxdc2-GFP ${ }^{+}$cells in steady-state and mobilized spleens from Plxdc2 $2^{+/ G F P}$ mice. (C) Experimental design of transplantation of mobilized spleen cells. (D) Chimerism kinetics of donor cells in the indicated lineages from the transplants in $\mathrm{C}$. 
Figure 4

A
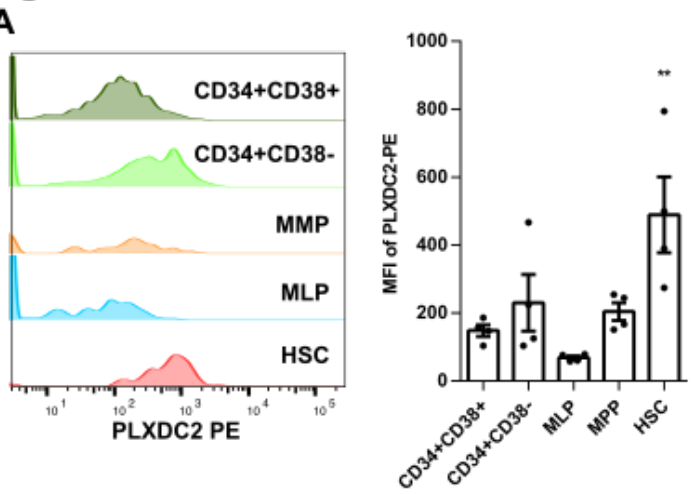

C

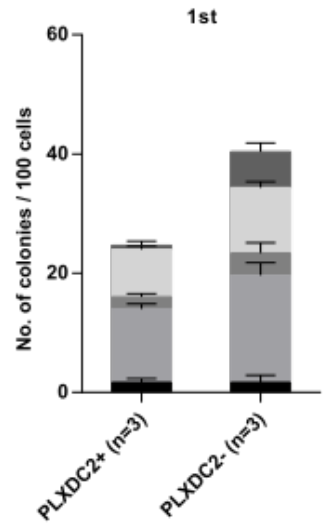

E

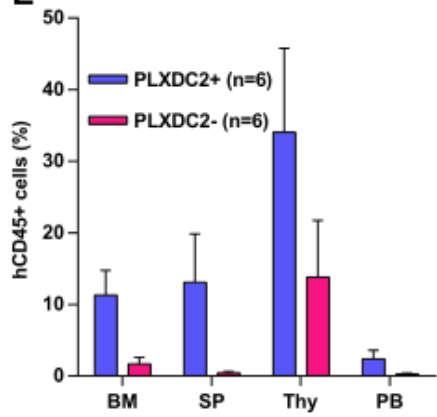

H

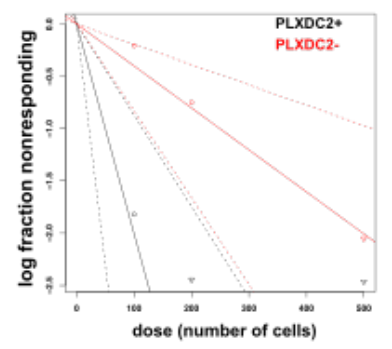

F
B

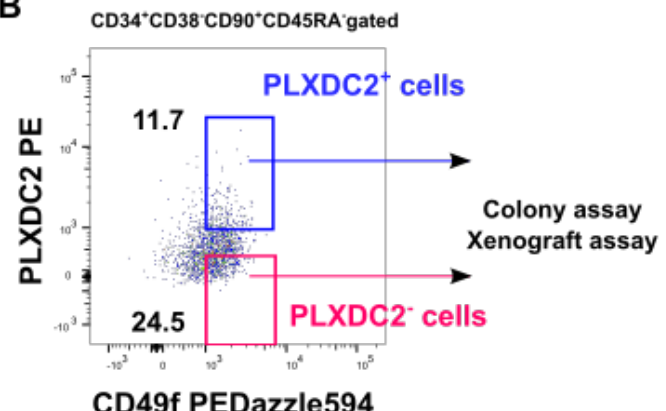

D
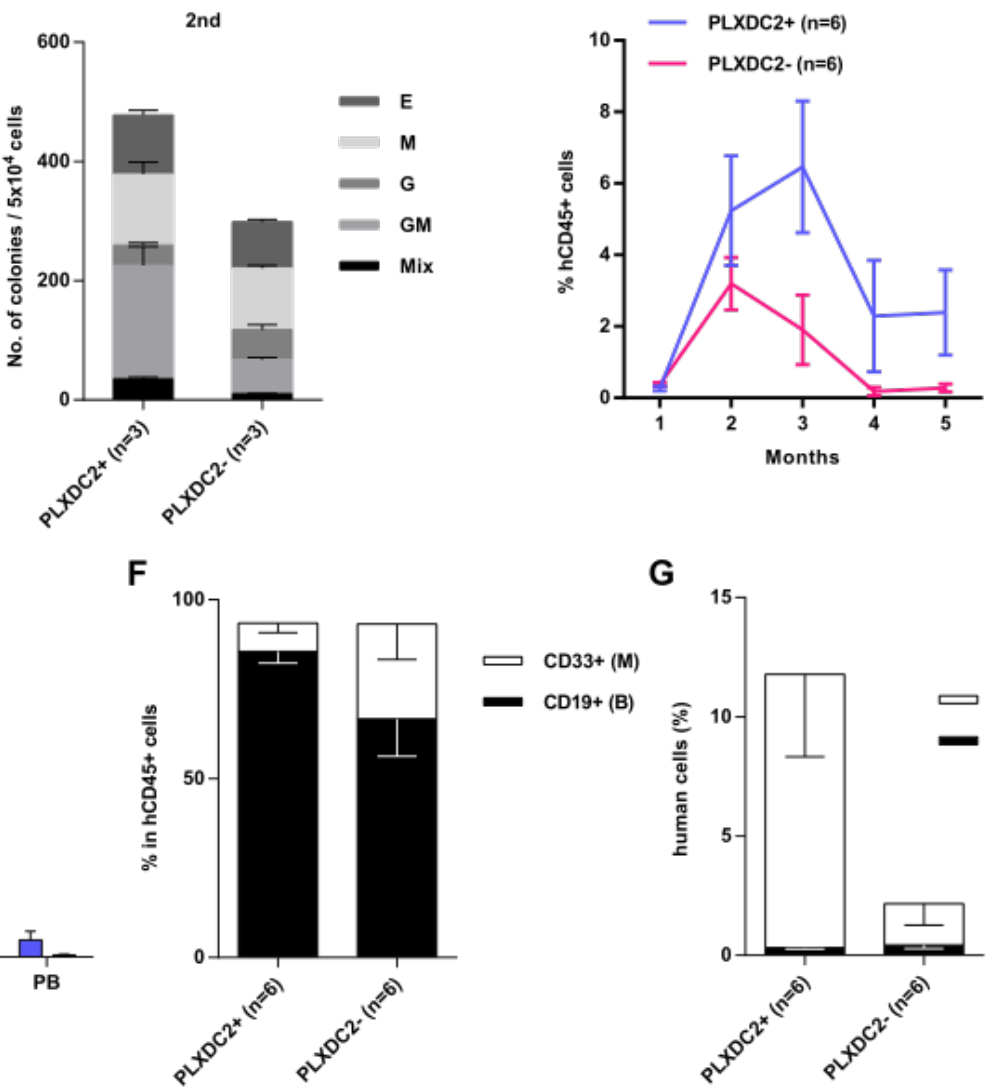

G

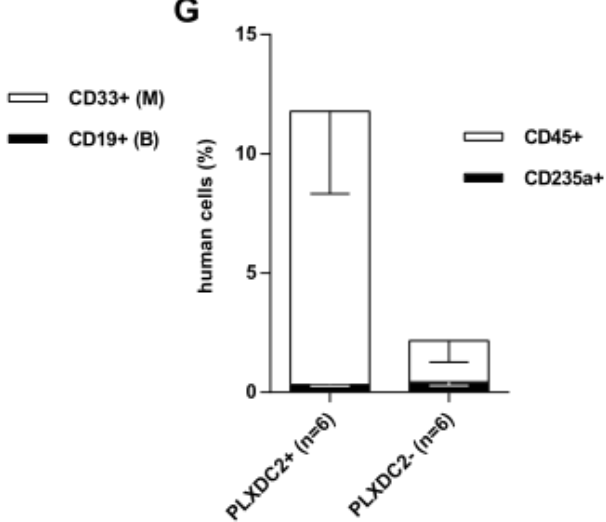




\section{Figure 4: Enrichment of human functional HSCs by PLXDC2 expression}

(A) PLXDC2 expression on the indicated cell types detected by anti-PLXDC2 antibody in human cord blood mononuclear cells. Left: representative FACS plots. Right: quantitative data from 4 different cord blood. (B) Representative FACS plots for gating PLXDC2 ${ }^{+}$HSCs and PLXDC2- HSCs. (C) Hematopoietic colony-forming assays using PLXDC2 $2^{+}$HSCs and PLXDC2- HSCs. $1^{\text {st }}$ colony assays (left: 100 cells/dish) and $2^{\text {nd }}$ colony assays (right: 50,000 cells/dish). (D) Kinetic analysis of peripheral blood engraftment (measured as percent of $\mathrm{CD}^{4} 5^{+}$cells) by PLXDC2 $2^{+} \mathrm{HSCs}$ and PLXDC2HSCs after transplantation into NSG mice (200 cells per recipient, $n=6$ each). (E) Engraftment of PLXDC2 $2^{+}$HSCs and PLXDC2 ${ }^{-}$HSCs assessed in NSG mice 20 weeks after transplant (PLXDC2+: $\mathrm{n}=16$ mice; PLXDC2-: $\mathrm{n}=14$ mice, 3 independent experiments). BM, bone marrow; SP, spleen; PB, peripheral blood. (F) Lineage potential of PLXDC2 $2^{+}$HSCs and PLXDC2- HSCs assessed in NSG mice 20 weeks after transplant. B cells (B: black bars) and myeloid cells (M: white bars). (G) The human graft consisted of CD235a $\mathrm{a}^{+}$erythroid (black bars) and CD45 ${ }^{+}$myelo-lymphoid cells (white bars). (H) Long-term repopulating cell frequency in $\mathrm{PLXDC}^{+} \mathrm{HSCs}$ and $\mathrm{PLXDC}^{-} \mathrm{HSCs}^{-}$ measured by LDA. 
bioRxiv preprint doi: https://doi.org/10.1101/2021.09.27.461900; this version posted September 27, 2021. The copyright holder for this preprint (which was not certified by peer review) is the author/funder, who has granted bioRxiv a license to display the preprint in perpetuity. It is made available under aCC-BY-NC-ND 4.0 International license.

\section{Figure 5}
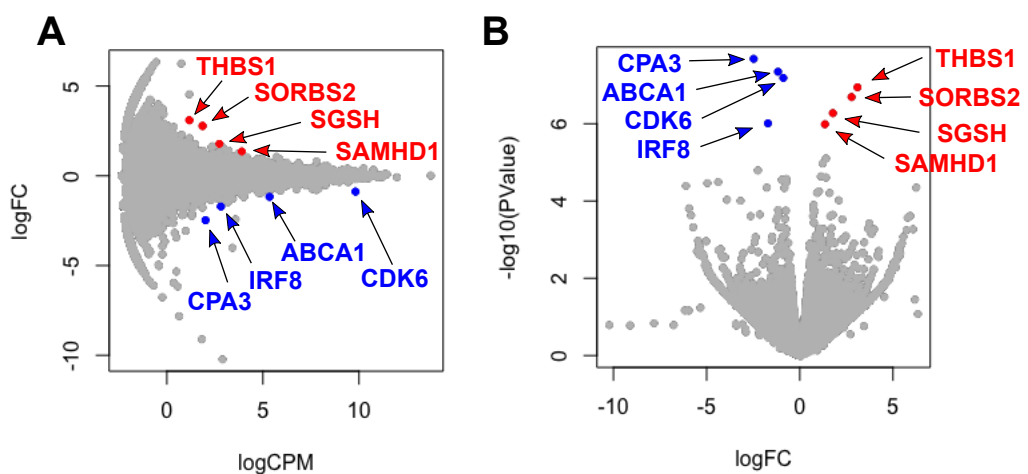

c

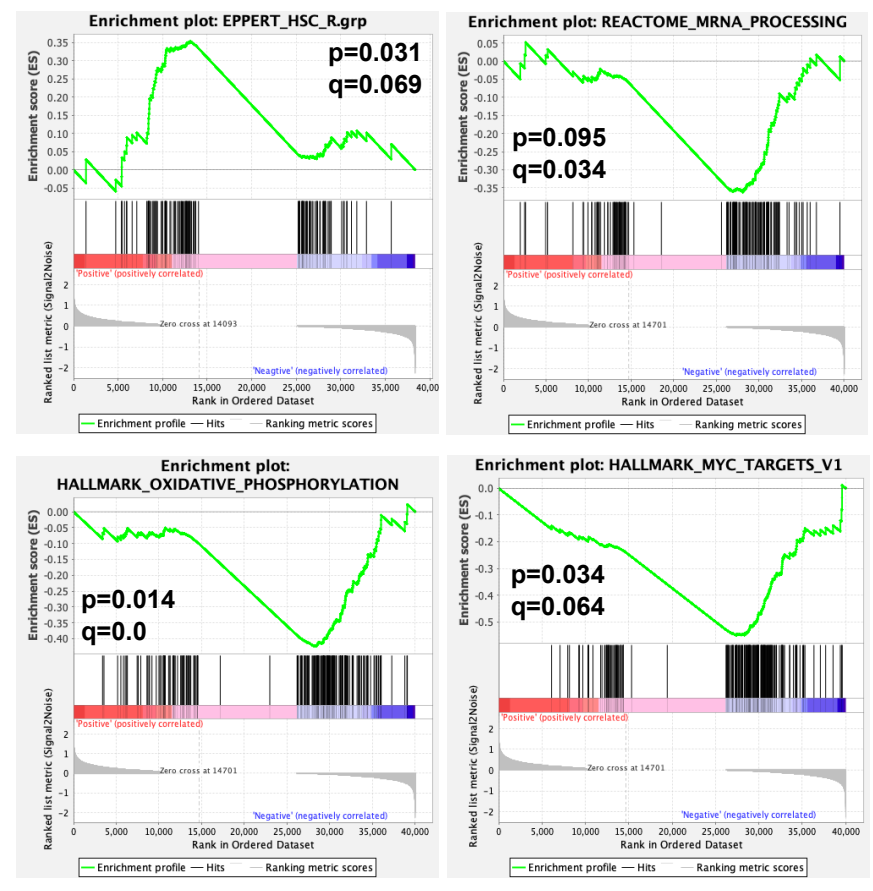




\section{Figure 5: PLXDC2 ${ }^{+}$HSCs show more HSC signature}

(A and B) The MA plot (A) and the volcano plot (B) show 8 genes differentially expressed

(4 genes upregulated in PLXDC2 ${ }^{+}$HSCs (red) and 4 genes upregulated in PLXDC2-

HSCs (blue), FDR $<0.05)$. (C) Gene set enrichment analysis (GSEA). NES = Normalized

Enrichment Score. PLXDC2 ${ }^{+}$HSCs versus PLXDC2- HSCs is represented. 


\section{Materials and methods}

\section{Quantitative PCR}

Total RNA was harvested from FACS-purified CD34-llow KSL cells, CD34+ ${ }^{+} \mathrm{KSL}$ progenitor cells, Gr- $1^{+}$neutrophils, Mac- $1^{+}$monocytes/macrophages, B220+ $\mathrm{B}$ cells, thymic $\mathrm{CD}^{+} \mathrm{CD}^{+} \mathrm{T}$ cells, TER $119^{+}$erythroblasts, or $\mathrm{CD} 41^{+}$megakaryocytes. Total RNA was then subjected to one round of in vitro transcription as described in the previous paragraph. Quantitative PCR was performed using a QuantiTect SYBR Green PCR kit (QIAGEN) according to the manufacturer's protocol. Each sample was normalized to hypoxanthine phosphoribosyl transferase.

\section{Hematopoietic progenitor assays}

Colony-forming activity (CFU-C) assays were performed using MethoCult M3434 (Stem Cell Technologies). A total of $2 \times 10^{4} \mathrm{BM}$ mononuclear cells (MNCs) were plated on 35 $\mathrm{mm}$ culture dishes and then incubated at $37^{\circ} \mathrm{C}$ in humidified chambers containing $5 \%$ $\mathrm{CO}_{2}$. Colonies were counted using a dissecting microscope after 10 to 14 days of culture.

\section{Long-term competitive reconstitution assay}

Test cells from $P l x d c 2^{+/+}, P l x d c 2^{+/ G F P}$, and Plxdc2 $2^{G F P / G F P}$ mice (CD45.2) were mixed with $2 \times 10^{5}$ CD45.1/CD45.2 adult BM MNCs and injected into adult recipient mice (CD45.1) irradiated at a dose of 9.5 Gy using a Cesium137 GammaCell40 Exactor Irradiator (MDS Nordia). Peripheral blood cells were stained with FITC-conjugated anti-CD45.1 antibodies, biotinylated anti-CD45.2 antibodies followed 
by APC-Cy7 streptavidin, PE-conjugated anti Mac-1 and Gr-1 antibodies, APCconjugated anti-CD4 and -CD8 antibodies, and PE-Cy7-conjugated anti-B220 antibodies. The test cell-derived chimerism was evaluated on a FACSCanto (BD Bioscience) system.

\section{Blood count}

Peripheral blood was collected and analyzed on an automated blood cell counter, KX-21

(Sysmex), according to the manufacturer's instructions.

\section{Human cord blood processing}

All experiments using human cord blood (CB) cells were approved by the Ethics Committee at the Institute of Medical Science, the University of Tokyo (approval number: 27-34-1225). Human CB cells were obtained from the Japanese Red Cross KantoKoshinetsu Cord Blood Bank (Tokyo, Japan) following an institutional review boardapproved protocol. Informed consent was obtained in accordance with the Declaration of Helsinki. Various cord blood samples were pooled and an equal volume of PBS/2\% FBS was added prior to layering on Lymphoprep ${ }^{\mathrm{TM}}$ (STEM CELL Tecnologies) in $50 \mathrm{~mL}$ conical tubes. Tubes were subjected to $30 \mathrm{~min}$ centrifugation at $800 \mathrm{xg}$ followed by careful removal of mononuclear layer and washed with PBS $/ 2 \%$ FBS. CD $34^{+}$cells were enriched by Direct $\mathrm{CD} 4^{+}$Progenitor Isolation Kit (Miltenyi Biotec) according to manufacture protocol. CD34 ${ }^{+}$cells were stored in liquid nitrogen.

\section{Cell preparation for cell sorting}


$\mathrm{CD}^{+}{ }^{+}$cells were stained with CD45RA (FITC, clone HI100), CD90 (APC/, clone 5E10), CD49f (PE-DazzleTM594, clone GoH3), CD34 (APC-Cy7, clone 581), CD38 (PE-Cy7, clone HIT2), Lineage marker cocktail (BV510, CD3/14/16/19/20//56, clone OKT3/M5E2/3G8/HIB19/2H7/HCD56) (BioLegend) and PLXDC2 (PE/APC, rabbit monoclonal clone 4G3) (Kyokuto Pharmaceutical Industrial Co. Ltd. and Abwiz Bio Inc.) and incubated for $30 \mathrm{~min}$ at $4^{\circ} \mathrm{C}$. Cells were washed with $\mathrm{PBS} / 2 \%$ FBS and stained with streptavidin conjugated BV605 (BioLegend) if CD90 biotin-conjugated antibody was used. Cells were subsequently washed and resuspended in PBS/2\% FBS prior to sort. Cells were sorted on FACS AriaII (Becton Dickinson) with a 100-micron nozzle operating mode and collected in $1.5 \mathrm{~mL}$ microtubes.

\section{Xenotransplant assays}

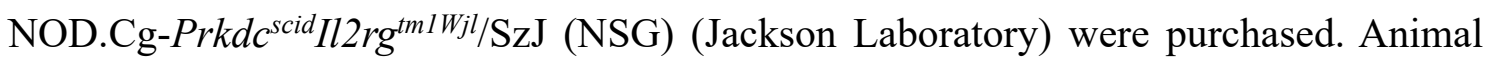
experiments were performed in accordance with institutional guidelines approved by University of Tokyo. Various cell doses of PLXDC2 ${ }^{+}$or PLXDC2- human HSCs were transplanted into $2.5 \mathrm{~Gy}$ irradiated NSG mice by tail vein injection.

\section{Assessment of human cell engraftment}

Bone marrow, thymus, peripheral blood and spleen from NSG mice were analyzed for human cell engraftment with CD45 (BV421, clone 2D1). Cells were stained in PBS/2\% FBS and analyzed by flow cytometry (FACSAriaII, Beckton Dickinson). Lineage committed cells in bone marrow, peripheral blood and spleen were analyzed with CD33 
(PE, clone P67.6), CD19 (PE-Cy7, clone HIB19), CD3 (FITC, clone OKT3). Thymocytes were analyzed with CD4 (FITC, clone OKT4) and CD8 (PE, clone HIT8a). Stem progenitor cells in bone marrow were analyzed with CD34, CD38, CD90, CD45RA, CD49f and PLXDC2. All antibodies used in this study were obtained from BioLegend unless otherwise indicated.

\section{Statics}

Statistical analysis was performed by unpaired Student's t test or two- or one-way ANOVA without correction for multiple comparison (Fisher LSD test). All data are presented as mean \pm SEM. Significance levels were set at $\mathrm{p}^{*}<0.05, \mathrm{p}^{* *}<0.01$ and $\mathrm{p}^{* * *}$ $<0.001$. For statistical analysis GraphPad Prism was used.

\section{RNASeq}

We performed RNA-Seq as described previously (Hayashi et al., 2018) with minor modification. In brief, using 100 sorted cells, the first strand of cDNA was synthesized by using PrimeScript RT reagent kit (TaKaRa Bio Inc.) and not-so random primers. Following the synthesis of the first strand, the second strand was synthesized by using Klenow Fragment (30,_50, exo-; New England Biolabs Inc.) and complement chains of not-so random primers. Using purified double-strand cDNA, the library for RNA-Seq was prepared and amplified using Nextera XT DNA sample Prep kit (Illumina Inc.). These prepared libraries were sequenced on Next-Seq system (Illumina Inc.), according to the manufacturer's instruction. In addition, each obtained read was mapped to the 
reference sequence "GRCh38" using CLC genomic workbench v11.0.0 (QIAGEN), and expression levels were normalized and subjected to the statistical analyses based on EdgeR. Transcriptome data were subjected to GSEA using GSEA v3.0.0 software, available from the Broad Institute (Subramanian et al., 2005). All Gene sets were obtained from the database of Broad Institute unless otherwise stated. Principle component analysis, hierarchal clustering analysis and visualization of gene expression or protein level were performed by Multi expression Viewer. 


\section{Reference}

Acar, M., Kocherlakota, K.S., Murphy, M.M., Peyer, J.G., Oguro, H., Inra, C.N., Jaiyeola, C., Zhao, Z., Luby-Phelps, K., Morrison, S.J., 2015. Deep imaging of bone marrow shows non-dividing stem cells are mainly perisinusoidal. Nature 526, 126-130. https://doi.org/10.1038/nature15250

Baccin, C., Al-Sabah, J., Velten, L., Helbling, P.M., Grünschläger, F., HernándezMalmierca, P., Nombela-Arrieta, C., Steinmetz, L.M., Trumpp, A., Haas, S., 2020. Combined single-cell and spatial transcriptomics reveal the molecular, cellular and spatial bone marrow niche organization. Nat Cell Biol 22, 38-48.

https://doi.org/10.1038/s41556-019-0439-6

Balazs, A.B., Fabian, A.J., Esmon, C.T., Mulligan, R.C., 2006. Endothelial protein C receptor (CD201) explicitly identifies hematopoietic stem cells in murine bone marrow. Blood 107, 2317-2321. https://doi.org/10.1182/blood-2005-06-2249

Batista, S., Maniati, E., Reynolds, L.E., Tavora, B., Lees, D.M., Fernandez, I., Elia, G., Casanovas, O., Celso, C.L., Hagemann, T., Hodivala-Dilke, K., 2014. Haematopoietic focal adhesion kinase deficiency alters haematopoietic homeostasis to drive tumour metastasis. Nat Commun 5, 5054. https://doi.org/10.1038/ncomms6054 Baum, C.M., Peault, B., 1992. Isolation of a candidate human hematopoietic stem-cell population. Proceedings of the National Academy of Sciences 89, 2804-2808.

Baum, C.M., Weissman, I.L., Tsukamoto, A.S., Buckle, A.M., Peault, B., 1992. Isolation of a candidate human hematopoietic stem-cell population. Proceedings of the National Academy of Sciences 89, 2804-2808. https://doi.org/10.1073/pnas.89.7.2804 Bhatia, M., Wang, J.C.Y., Kapp, U., Bonnet, D., Dick, J.E., 1997. Purification of primitive human hematopoietic cells capable of repopulating immune-deficient mice. Proceedings of the National Academy of Sciences 94, 5320-5325.

Bianchi, E., Sun, Y., Almansa-Ordonez, A., Woods, M., Goulding, D., MartinezMartin, N., Wright, G.J., 2021. Control of oviductal fluid flow by the G-protein coupled receptor Adgrd1 is essential for murine embryo transit. Nat Commun 12, 1251. https://doi.org/10.1038/s41467-021-21512-w

Cabezas-Wallscheid, N., Buettner, F., Sommerkamp, P., Klimmeck, D., Ladel, L., Thalheimer, F.B., Pastor-Flores, D., Roma, L.P., Renders, S., Zeisberger, P., Przybylla, A., Schönberger, K., Scognamiglio, R., Altamura, S., Florian, C.M., Fawaz, M., 
Vonficht, D., Tesio, M., Collier, P., Pavlinic, D., Geiger, H., Schroeder, T., Benes, V., Dick, T.P., Rieger, M.A., Stegle, O., Trumpp, A., 2017. Vitamin A-Retinoic Acid Signaling Regulates Hematopoietic Stem Cell Dormancy. Cell 169, 807-823.e19. https://doi.org/10.1016/j.cell.2017.04.018

Chao, M.P., Seita, J., Weissman, I.L., 2008. Establishment of a Normal Hematopoietic and Leukemia Stem Cell Hierarchy. Cold Spring Harbor Symposia on Quantitative Biology 73, 439-449. https://doi.org/10.1101/sqb.2008.73.031

Chen, C-Z., Li, M., de Graaf, D., Monti, S., Göttgens B., Sanchez, M-J., Lander, E.S., Golub, T.R., Green, A.R., Lodish, H.F., 2002. Identification of endoglin as a functional marker that defines long-term repopulating hematopoietic stem cells. Proceedings of the National Academy of Sciences 99, 15468-15473.

Chen, J.Y., Miyanishi, M., Wang, S.K., Yamazaki, S., Sinha, R., Kao, K.S., Seita, J., Sahoo, D., Nakauchi, H., Weissman, I.L., 2016. Hoxb5 marks long-term haematopoietic stem cells and reveals a homogenous perivascular niche. Nature 530, 223-227. https://doi.org/10.1038/nature16943

Cheng, G., Zhong, M., Kawaguchi, R., Kassai, M., Al-Ubaidi, M., Deng, J., TerStepanian, M., Sun, H., 2014. Identification of PLXDC1 and PLXDC2 as the transmembrane receptors for the multifunctional factor PEDF. eLife 3, e05401. https://doi.org/10.7554/eLife.05401

Christensen, J.L., Weissman, I.L., 2001. Flk-2 is a marker in hematopoietic stem cell differentiation: A simple method to isolate long-term stem cells. Proceedings of the National Academy of Sciences 98, 14541-14546.

https://doi.org/10.1073/pnas.261562798

Craig, W., Kay, R., Cutler, R.L., Lansdorp, P.M., 1993a. Expression of Thy-1 on human hematopoietic progenitor cells. Journal of Experimental Medicine 177, 1331-1342. https://doi.org/10.1084/jem.177.5.1331

Dislich, B., Wohlrab, F., Bachhuber, T., Müller, S.A., Kuhn, P.-H., Hogl, S., MeyerLuehmann, M., Lichtenthaler, S.F., 2015. Label-free Quantitative Proteomics of Mouse Cerebrospinal Fluid Detects $\beta$-Site APP Cleaving Enzyme (BACE1) Protease

Substrates In Vivo. Molecular \& Cellular Proteomics 14, 2550-2563.

https://doi.org/10.1074/mcp.M114.041533

Fares, I., Chagraoui, J., Gareau, Y., Gingras, S., Ruel, R., Mayotte, N., Csaszar, E., Knapp, D.J.H.F., Miller, P., Ngom, M., Imren, S., Roy, D.-C., Watts, K.L., Kiem, H.-P., 
Herrington, R., Iscove, N.N., Humphries, R.K., Eaves, C.J., Cohen, S., Marinier, A., Zandstra, P.W., Sauvageau, G., 2014. Pyrimidoindole derivatives are agonists of human hematopoietic stem cell self-renewal. Science 345, 1509-1512.

https://doi.org/10.1126/science.1256337

Fares, I., Chagraoui, J., Lehnertz, B., MacRae, T., Mayotte, N., Tomellini, E., Aubert, L., Roux, P.P., Sauvageau, G., 2017. EPCR expression marks UM171-expanded CD34+ cord blood stem cells. Blood 129, 3344-3351. https://doi.org/10.1182/blood-2016-11750729

Fukushima, T., Tanaka, Y., Hamey, F.K., Chang, C.-H., Oki, T., Asada, S., Hayashi, Y., Fujino, T., Yonezawa, T., Takeda, R., Kawabata, K.C., Fukuyama, T., Umemoto, T., Takubo, K., Takizawa, H., Goyama, S., Ishihama, Y., Honda, H., Göttgens, B., Kitamura, T., 2019. Discrimination of Dormant and Active Hematopoietic Stem Cells by G0 Marker Reveals Dormancy Regulation by Cytoplasmic Calcium. Cell Reports 29, 4144-4158. https://doi.org/10.1016/j.celrep.2019.11.061

Gazit, R., Mandal, P.K., Ebina, W., Ben-Zvi, A., Nombela-Arrieta, C., Silberstein, L.E., Rossi, D.J., 2014. Fgd5 identifies hematopoietic stem cells in the murine bone marrow. Journal of Experimental Medicine 211, 1315-1331.

https://doi.org/10.1084/jem.20130428

Georgantas, R.W., Tanadve, V., Malehorn, M., Heimfeld, S., Chen, C., Carr, L., Martinez-Murillo, F., Riggins, G., Kowalski, J., Civin, C.I., 2004. Microarray and Serial Analysis of Gene Expression Analyses Identify Known and Novel Transcripts Overexpressed in Hematopoietic Stem Cells. Cancer Res 64, 4434-4441.

https://doi.org/10.1158/0008-5472.CAN-03-3247

Hao, Q., Shah, A., Thiemann, F., Smogorzewska, E., Crooks, G., 1995. A functional comparison of CD34 + CD38- cells in cord blood and bone marrow. Blood 86, 37453753. https://doi.org/10.1182/blood.V86.10.3745.bloodjournal86103745

Hayashi, T., Ozaki, H., Sasagawa, Y., Umeda, M., Danno, H., Nikaido, I., 2018. Singlecell full-length total RNA sequencing uncovers dynamics of recursive splicing and enhancer RNAs. Nat Commun 9, 619. https://doi.org/10.1038/s41467-018-02866-0 Hemming, M.L., Elias, J.E., Gygi, S.P., Selkoe, D.J., 2008. Proteomic Profiling of $\gamma$ Secretase Substrates and Mapping of Substrate Requirements. PLOS Biology 6, e257. https://doi.org/10.1371/journal.pbio.0060257

Hrecka, K., Hao, C., Gierszewska, M., Swanson, S.K., Kesik-Brodacka, M., Srivastava, 
S., Florens, L., Washburn, M.P., Skowronski, J., 2011. Vpx relieves inhibition of HIV-1 infection of macrophages mediated by the SAMHD1 protein. Nature 474, 658-661. https://doi.org/10.1038/nature10195

Ishibashi, T., Yokota, T., Tanaka, H., Ichii, M., Sudo, T., Satoh, Y., Doi, Y., Ueda, T., Tanimura, A., Hamanaka, Y., Ezoe, S., Shibayama, H., Oritani, K., Kanakura, Y., 2016. ESAM is a novel human hematopoietic stem cell marker associated with a subset of human leukemias. Experimental Hematology 44, 269-281.e1.

https://doi.org/10.1016/j.exphem.2015.12.010

Kiel, M.J., Yilmaz, Ö.H., Iwashita, T., Yilmaz, O.H., Terhorst, C., Morrison, S.J., 2005. SLAM Family Receptors Distinguish Hematopoietic Stem and Progenitor Cells and Reveal Endothelial Niches for Stem Cells. Cell 121, 1109-1121.

Kubota, Y., Osawa, M., Jakt, L.M., Yoshikawa, K., Nishikawa, S.-I., 2009. Necdin restricts proliferation of hematopoietic stem cells during hematopoietic regeneration. Blood 114, 4383-4392. https://doi.org/10.1182/blood-2009-07-230292 Kurotaki, D., Nakabayashi, J., Nishiyama, A., Sasaki, H., Kawase, W., Kaneko, N., Ochiai, K., Igarashi, K., Ozato, K., Suzuki, Y., Tamura, T., 2018. Transcription Factor IRF8 Governs Enhancer Landscape Dynamics in Mononuclear Phagocyte Progenitors. Cell Reports 22, 2628-2641. https://doi.org/10.1016/j.celrep.2018.02.048

Kurotaki, D., Osato, N., Nishiyama, A., Yamamoto, M., Ban, T., Sato, H., Nakabayashi, J., Umehara, M., Miyake, N., Matsumoto, N., Nakazawa, M., Ozato, K., Tamura, T., 2013. Essential role of the IRF8-KLF4 transcription factor cascade in murine monocyte differentiation. Blood 121, 1839-1849. https://doi.org/10.1182/blood-2012-06-437863 Laguette, N., Sobhian, B., Casartelli, N., Ringeard, M., Chable-Bessia, C., Ségéral, E., Yatim, A., Emiliani, S., Schwartz, O., Benkirane, M., 2011. SAMHD1 is the dendriticand myeloid-cell-specific HIV-1 restriction factor counteracted by Vpx. Nature 474, 654-657. https://doi.org/10.1038/nature10117

Laurenti, E., Frelin, C., Xie, S., Ferrari, R., Dunant, C.F., Zandi, S., Neumann, A., Plumb, I., Doulatov, S., Chen, J., April, C., Fan, J.-B., Iscove, N., Dick, J.E., 2015. CDK6 Levels Regulate Quiescence Exit in Human Hematopoietic Stem Cells. Cell Stem Cell 16, 302-313. https://doi.org/10.1016/j.stem.2015.01.017 Loeffler, D., Wehling, A., Schneiter, F., Zhang, Y., Müller-Bötticher, N., Hoppe, P.S., Hilsenbeck, O., Kokkaliaris, K.D., Endele, M., Schroeder, T., 2019. Asymmetric lysosome inheritance predicts activation of haematopoietic stem cells. Nature 573, 426- 
429. https://doi.org/10.1038/s41586-019-1531-6

Lu et al. - 2012 - Fak depletion in both hematopoietic and nonhematop.pdf, n.d.

Majeti, R., Park, C.Y., Weissman, I.L., 2007. Identification of a Hierarchy of

Multipotent Hematopoietic Progenitors in Human Cord Blood. Cell Stem Cell 1, 635645. https://doi.org/10.1016/j.stem.2007.10.001

Mayani, H., Dragowska, W., 1993. Characterization of Functionally Distinct

Subpopulations of CD34+ Cord Blood Cells in Serum-Free Long-Term Cultures

Supplemented With Hematopoietic Cytokines. Blood 82, 2664-2672.

Miller, S.F.C., Summerhurst, K., Rünker, A.E., Kerjan, G., Friedel, R.H., Chédotal, A., Murphy, P., Mitchell, K.J., 2007. Expression of Plxdc2/TEM7R in the developing nervous system of the mouse. Gene Expression Patterns 7, 635-644.

https://doi.org/10.1016/j.modgep.2006.12.002

Miller-Delaney, S.F.C., Lieberam, I., Murphy, P., Mitchell, K.J., 2011. Plxdc2 Is a

Mitogen for Neural Progenitors. PLoS ONE 6, e14565.

https://doi.org/10.1371/journal.pone.0014565

Morita, Y., Ema, H., Nakauchi, H., 2010. Heterogeneity and hierarchy within the most primitive hematopoietic stem cell compartment. Journal of Experimental Medicine 207, 1173-1182. https://doi.org/10.1084/jem.20091318

Murphy-Ullrich, J.E., Poczatek, M., 2000. Activation of latent TGF-b by thrombospondin-1: mechanisms and physiology 11.

Nestorowa, S., Hamey, F.K., Pijuan Sala, B., Diamanti, E., Shepherd, M., Laurenti, E., Wilson, N.K., Kent, D.G., Göttgens, B., 2016. A single-cell resolution map of mouse hematopoietic stem and progenitor cell differentiation. Blood 128, e20-e31. https://doi.org/10.1182/blood-2016-05-716480

Notta, F., Doulatov, S., Laurenti, E., Poeppl, A., Jurisica, I., Dick, J.E., 2011. Isolation of Single Human Hematopoietic Stem Cells Capable of Long-Term Multilineage Engraftment. Science 333, 218-221. https://doi.org/10.1126/science.1201219 Ooi, A.G.L., Karsunky, H., Majeti, R., Butz, S., Vestweber, D., Ishida, T., Quertermous, T., Weissman, I.L., Forsberg, E.C., 2009. The Adhesion Molecule Esam1 Is a Novel Hematopoietic Stem Cell Marker. Stem Cells 27, 653-661.

https://doi.org/10.1634/stemcells.2008-0824

Osawa, M., Hanada, K. -i., Hamada, H., Nakauchi, H., 1996. Long-Term Lymphohematopoietic Reconstitution by a Single CD34-Low/Negative Hematopoietic 
Stem Cell. Science 273, 242-245. https://doi.org/10.1126/science.273.5272.242

Seita, J., Sahoo, D., Rossi, D.J., Bhattacharya, D., Serwold, T., Inlay, M.A., Ehrlich, L.I.R., Fathman, J.W., Dill, D.L., Weissman, I.L., 2012. Gene Expression Commons: An Open Platform for Absolute Gene Expression Profiling. PLoS ONE 7, e40321. https://doi.org/10.1371/journal.pone.0040321

Shimizu, H., Nakagawa, M., Todaka, N., Imaizumi, K., Kurosawa, Y., Maruyama, T., Okumura, C.J., Shibata, T., Tanaka, Y., Sato, Y., Ono, Y., Akuta, T., 2018. Improving the quality of a recombinant rabbit monoclonal antibody against PLXDC2 by optimizing transient expression conditions and purification method. Protein Expression and Purification 146, 27-33. https://doi.org/10.1016/j.pep.2018.01.011

Spangrude, G.J., 1995. Long-Term Repopulation of Irradiated Mice With Limiting Numbers of Purified Hematopoietic Stem Cells: In Vivo Expansion of Stem Cell Phenotype But Not Function. Blood 85, 11.

Spangrude, G.J., Heimfeld, S., Weissman, I.L., 1988. Purification and Characterization of Mouse Hematopoietic Stem Cells. Science 241, 58-62.

Subramanian, A., Tamayo, P., Mootha, V.K., Mukherjee, S., Ebert, B.L., Gillette, M.A., Paulovich, A., Pomeroy, S.L., Golub, T.R., Lander, E.S., Mesirov, J.P., 2005. Gene set enrichment analysis: A knowledge-based approach for interpreting genome-wide expression profiles. Proceedings of the National Academy of Sciences 102, 1554515550. https://doi.org/10.1073/pnas.0506580102

Tubau-Juni, N., Bassaganya-Riera, J., Leber, A., Zoccoli-Rodriguez, V., Kronsteiner, B., Viladomiu, M., Abedi, V., Philipson, C.W., Hontecillas, R., 2020. Identification of new regulatory genes through expression pattern analysis of a global RNA-seq dataset from a Helicobacter pylori co-culture system. Sci Rep 10, 11506.

https://doi.org/10.1038/s41598-020-68439-8

Visser, J.W., Bauman, J.G., Mulder, A.H., Eliason, J.F., de Leeuw, A.M., 1984.

Isolation of murine pluripotent hemopoietic stem cells. Journal of Experimental Medicine 159, 1576-1590. https://doi.org/10.1084/jem.159.6.1576

Wang, B., Golemis, E.A., Kruh, G.D., 1997. ArgBP2, a Multiple Src Homology 3

Domain-containing, Arg/Abl-interacting Protein, Is Phosphorylated in v-Abl-

transformed Cells and Localized in Stress Fibers and Cardiocyte Z-disks. J. Biol. Chem. 272, 17542-17550. https://doi.org/10.1074/jbc.272.28.17542

Wu, X., Dao Thi, V.L., Huang, Y., Billerbeck, E., Saha, D., Hoffmann, H.-H., Wang, 
Y., Silva, L.A.V., Sarbanes, S., Sun, T., Andrus, L., Yu, Y., Quirk, C., Li, M., MacDonald, M.R., Schneider, W.M., An, X., Rosenberg, B.R., Rice, C.M., 2018. Intrinsic Immunity Shapes Viral Resistance of Stem Cells. Cell 172, 423-438.e25. https://doi.org/10.1016/j.cell.2017.11.018

Yamamoto, R., Morita, Y., Ooehara, J., Hamanaka, S., Onodera, M., Rudolph, K.L., Ema, H., Nakauchi, H., 2013. Clonal Analysis Unveils Self-Renewing LineageRestricted Progenitors Generated Directly from Hematopoietic Stem Cells. Cell 154, 1112-1126. https://doi.org/10.1016/j.cell.2013.08.007

Yamazaki, S., Ema, H., Karlsson, G., Yamaguchi, T., Miyoshi, H., Shioda, S., Taketo, M.M., Karlsson, S., Iwama, A., Nakauchi, H., 2011. Nonmyelinating Schwann Cells Maintain Hematopoietic Stem Cell Hibernation in the Bone Marrow Niche. Cell 147, 1146-1158. https://doi.org/10.1016/j.cell.2011.09.053

Yokota, T., Oritani, K., Butz, S., Kokame, K., Kincade, P.W., Miyata, T., Vestweber, D., Kanakura, Y., 2009. The endothelial antigen ESAM marks primitive hematopoietic progenitors throughout life in mice. Blood 113, 2914-2923.

https://doi.org/10.1182/blood-2008-07-167106

Zhao, L., Wang, W., Huang, S., Yang, Z., Xu, L., Yang, Q., Zhou, X., Wang, J., Shen, Q., Wang, C., Le, X., Feng, M., Zhou, N., Lau, W.B., Lau, B., Yao, S., Yi, T., Wang, X., Zhao, X., Wei, Y., Zhou, S., 2018. The RNA binding protein SORBS2 suppresses metastatic colonization of ovarian cancer by stabilizing tumor-suppressive immunomodulatory transcripts. Genome Biol 19, 35. https://doi.org/10.1186/s13059018-1412-6 